\title{
The influence of the number of rotor blades on the performance of orthopter wind turbine
}

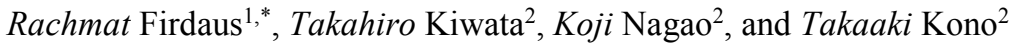 \\ ${ }^{1}$ Universitas Muhammadiyah Sidoarjo, Mechanical Engineering, Indonesia \\ ${ }^{2}$ Kanazawa University, Research Center for Sustainable Energy and Technology, Japan
}

\begin{abstract}
This paper describes the influence of the number of rotor blades the performance of the orthopter wind turbine. The orthopter wind turbine is combination between a drag-type and a lift-type vertical axis wind turbine which each blade combines a rotating movement around its own axis and a rotating movement around turbine's axis. In this case, the pitch of the blades was controlled by using a chain and sprockets arrangement to ensure that the blades rotated around their own axis by 360 degrees during the each two full revolution of the main rotor. To improve the performance of this wind turbine, the number of blades, was investigated by wind tunnel. By conducting two-dimensional unsteady CFD simulations, the power and torque of the vertical axis wind turbine and the flow around blades were also analyzed. The numerical simulation by using turbulence model predicted good agreement of the performance with experiment qualitatively.
\end{abstract}

\section{Introduction}

Wind energy is one of renewable energy resources which plays an important role in response to shortage of fossil fuels and climate change [1]. The world market for small wind turbine has seen further strength growth and common applications of one include; residential, hybrid system, fishery, commercial and industrial [2]. Recently, vertical-axis wind turbines (VAWTs) have received great enthusiasm for both off-shore applications in wind energy harvesting [3,4]. The VAWTs have many advantages, such as being omni-directional without needing a yaw control system and having lower sound emissions $[5,6]$. The vertical axis wind turbine can be classified into two groups according to the method of power generation. The first group is called lift-based power generation such as; Darrieus wind turbine and its variants. The second group is called drag-based power generation such as; Savonius wind turbine and its variants. The concept of the orthopter wind turbine is combination of both lift and drag-based power generation. The purpose of the design is to eliminate negative drag and thus positive power contribution of each blade in one rotational cycle. The different geometries of Savonius wind turbine are experimentally studied in order to determine the most effective operation parameters and it was found that, the two blades rotor is more efficient than three and four ones [7].The vertical axis wind turbine lift- base power has wide range angle of attack (AoA) in one cycle experiences [8]. The angle of attack of blade rotor beyond the stall of AoA and reduce positive torque generation. Reducing the angle of attack improves the torque coefficient, especially in the upwind area and some areas downstream of TheVAWT with variablepitch blades [9]. One of modification of this type is pitch angle adjusting of blades rotor turbines. Hwang et.al [10] by optimizing the pitch angle, the lift force increased and power generation increased by 30 percent compared to fixed pitch angle. The author has found that the power coefficient of a VAWT with variable-pitch straight blades that utilize a linkage mechanism is better than one with fixed-pitch blades [11]. The orthopter expected to create positively contributing torque on each blade at every azimuth position due to a rotating movement around its own axis. A previous study by Bayeul et, al [12] confirmed that The performance of this kind of turbine was better than those of classical VAWTs for some specific blade stagger. The arrangement of diffuser of the orthopter study by Shimizu [13] confirmed that the arrangement of diffuser on the top and both sides has good performance. The purpose of the author's is to investigate of the effects of number of blade and tip speed ratio corresponding to performances by experiments and numerical study.

\section{Methodology}

\subsection{Experiment setup}

Figure 1 shows the apparatus of experiments. The experiments were carried out in an open circuit wind tunnel which has cross section area $1250 \mathrm{~mm} \times 1250 \mathrm{~mm}$. Wind turbine connect with motor and torque meter. Wind speed measurement use to a thermal probe velocity

\footnotetext{
* Corresponding author: firdausr@umsida.ac.id
} 
anemometer.The torque is measured using the torque transducer and converter coupled with the main shaft. Turbine torque $(T)$ was measured at required rotational speeds. A turbine was driven by the variable speed motor under constant wind velocity $V_{\infty}=10 \mathrm{~m} / \mathrm{s}$. The rotor of blade using flat plate with thickness ratio $12.5 \%$ at $\mathrm{t}=$ $50 \mathrm{~mm}$. the number of blades are $\mathrm{n}=2, \mathrm{n}=3$, and $\mathrm{n}=4$. The chord length and length of span are $C_{1}=400 \mathrm{~mm}, C_{l}=$ $400 \mathrm{~mm}, C_{l}=400 \mathrm{~mm}, L_{l}=400 \mathrm{~mm}, L_{2}=290 \mathrm{~mm}$, and $L_{3}=228$ respectively. Experimental value is taken into account losses due to air resistance of the arm and mechanical loss. The main component of the orthopter wind turbine are blade, shaft, arm, chain and sprocket.

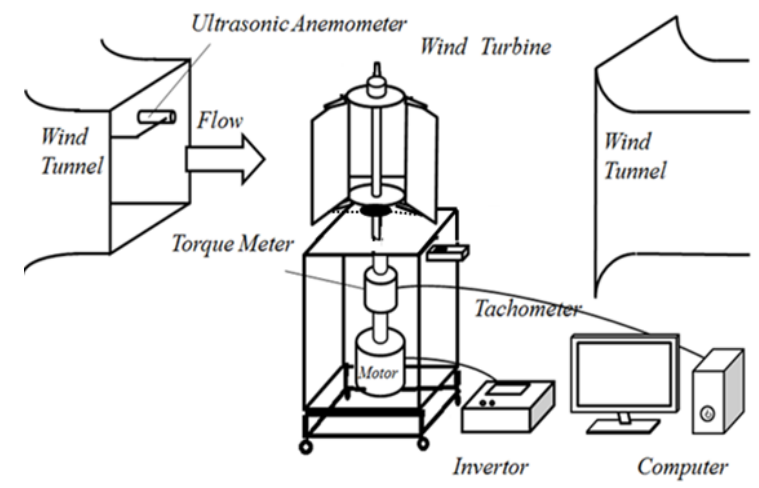

Fig.1. Schematic of Experiment apparatus.

\subsection{Numerical Technique}

The computational domain and the boundary conditions are shown in Figure 2. The computational domain consists of three mesh zones. one fixed sub-domain outside the rotor, one dynamic sub-domain around the rotor, and three dynamic sub-domains around the blades with equal spacing of $180^{\circ}, 120^{\circ}$, and $90^{\circ}$ for number of blade $n=2, n=3$, and $n=4$ respectively. Assuming a twodimensional, unsteady, incompressible, viscous flow, and no slip condition on the surface rotor. The $k$ - $\varepsilon R N G$ turbulence model was used.

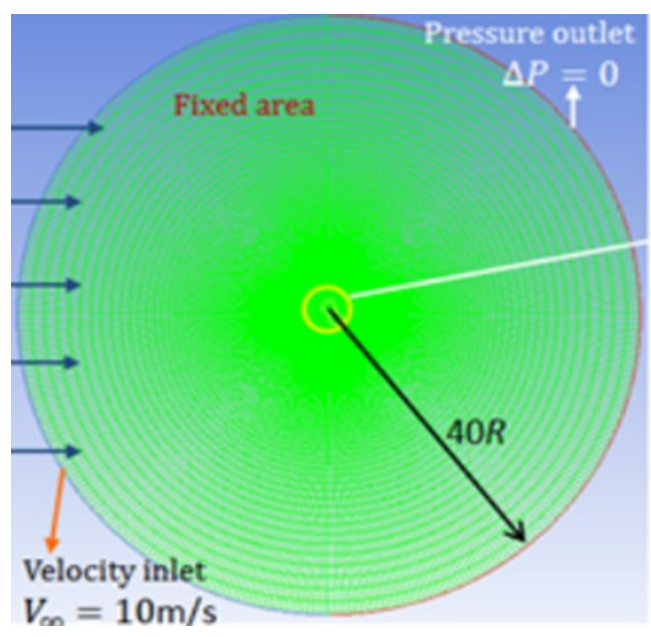

Fig. 2. The meshing grid and boundary condition.

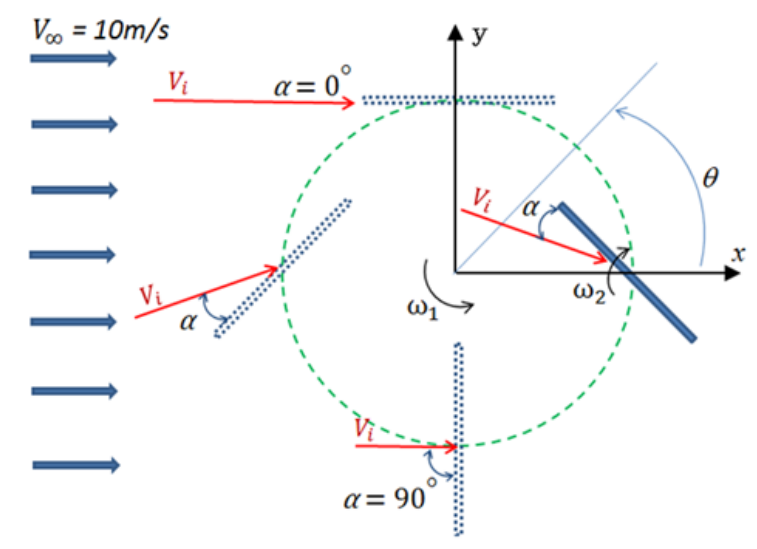

Fig. 3. The blade position at various azimuth angle corresponding to AoA.

The rotation of the four dynamic sub-domains can be controlled independently by a user-defined function (UDF), which is programmed in $\mathrm{C}++$ code. The schematic of the blade position at various azimuth angle corresponding to AoA was shown in Figure $2 b$.

\section{Result and Discussion}

\subsection{Power coefficient of experiment and numerical results}

Figure 3. shows the influences of number of blades of rotor and tip speed ratio corresponding to the coefficient performance and torque coefficient. The highest performance is the rotors which have three and four blades compared to the rotor have two blades. The peak of coefficient performance for the rotor have two, three, and four blades occur at $\lambda \approx 0.4$ which the rotor have two blades, the peak of performance coefficient shift to right slightly. The influence of number of blades was not significant for high tip speed ratio especially $\lambda \geq 0.4$ due to wake effects. The effect of number of blade of $\mathrm{V}$ axis Sail wing was done by Nemoto et al [11] which the highest performance was the rotor have four blades. The simulation can predict the performance of VAWT affected by number of blades rotor as shown in Figure $3 \mathrm{~b}$. The patterns of performance coefficient have a good agreement with experiment result. However, there are small differences of performance affected by number of blades which the lowest performance is the rotor has two blades. The values of $C p$ of numerical results was higher compare with $C p$ of experiment result due to many factor such as two dimensional, effect tip vortices, smooth surface of blades, and etc. The power coefficients increased as increase tip speed ratio until $\lambda=0.4$ and decrease as increase tip speed ratio for both experiment and numerical results. This confirmed by numerical results for straight blades with zero stagger angles by Bayeul et al [4] which the peak of power coefficient occur at tip speed ratio $\lambda=0.4$. 


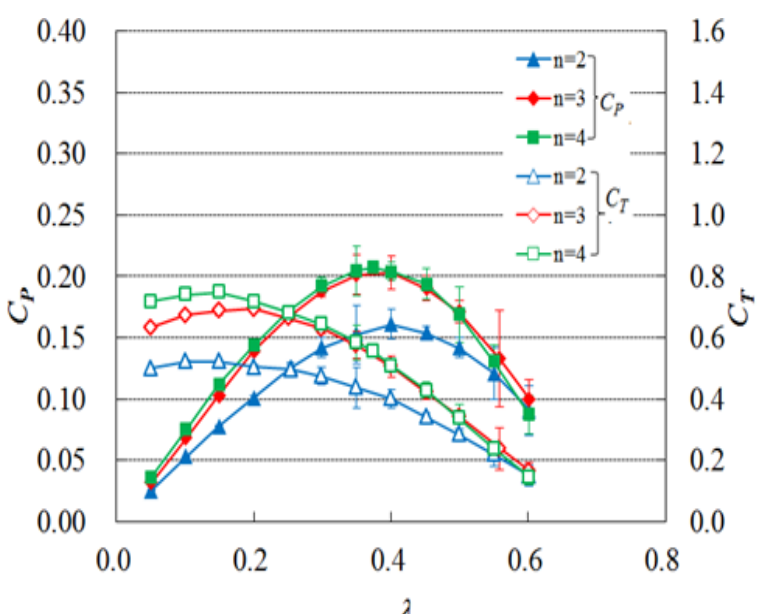

Fig. 4. Performances of experiment result.

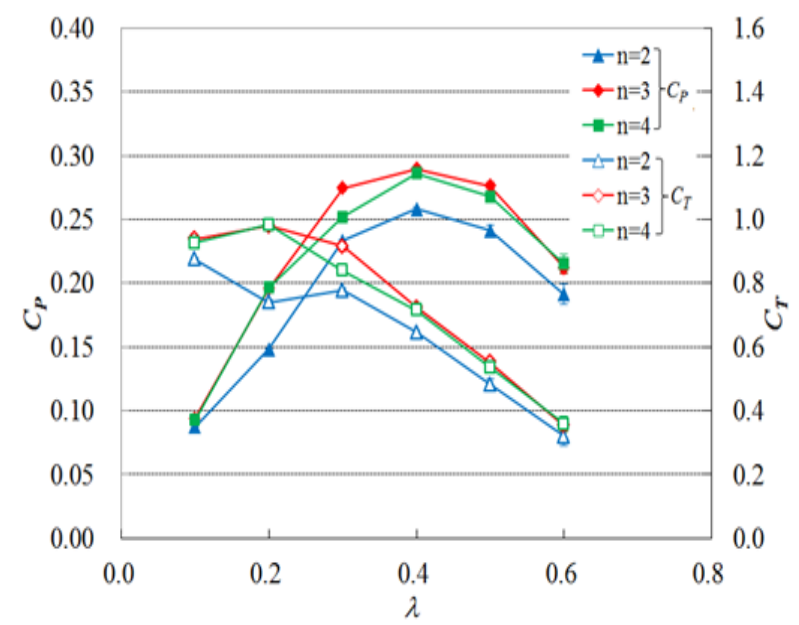

Fig. 5. Performances of numerical result.

\subsection{The number of blade effect on the torque coefficient}

The vertical axis wind turbine has high positive torque zone (HTZ) which this position high torque generate corresponding azimuth position based on type of wind turbine. For instant, the lift type VAWT has HTZ between $\theta=120^{\circ}$ and $\theta=270^{\circ}$ and for the drag- type VAWT has HTZ between $\theta=180^{\circ}$ and $\theta=360^{\circ}$. The orthopter wind turbine has combination for both type and has wide range of HTZ. In previously, tip speed ratio affect to HTZ start which high tip speed ratio has delay start. Figure 4 and Figure 5 show the effects of number of blade lead torque coefficient for tip speed ratio $\lambda=0.4$ and $\lambda=0.6$ respectively. There are different start of HTZ for number of blade $n=2, n=3$, and $n=4$ which first start is $n=2$ followed by $n=3$ and $n=4$. The start delay of HTZ for $n=3$ and $n=4$ due to affected by previously blade which create disturbance of induced flow. The effect of tip speed ratio and number of blade as seen in Figure 4. which the different torque for $n=2, n=3$, and $n=4$ slightly decrease compare to low tip speed ratio $\lambda=0.4$ in Figure 4. The most significant difference between twoand three-bladed rotors or more is that the rotor torque ripple, which has a distinctive twice-per-revolution oscillation for a two-bladed VAWT, is almost eliminated in a three-bladed rotor or more [8].

\section{Conclusion}

The effects of number of blade on the performance of the orthopter were investigated by wind tunnel experiment and the unsteady flow around the blades and predict performance influences by TSR and number of blade were investigated using a two-dimensional numerical simulation. The following conclusions can be reveal:

1. The prediction of performance by numerical simulation using the RNG $k-\varepsilon$ turbulence model qualitatively agrees with the experiment. It was found that the performance affected by number of blades and tip speed ratios.

2. The high tip speed ratio lead to reducing torque generation specially at downstream area

3. The simulations show effects of number of blade on the performance. The high number of blade reduce torque generation of one blade. However, the overall of performance is increased

I would like to give thanks for our research to Yoshiaki Sawade and Yurie Koami from Daido Company Ltd.

\section{References}

1. S. C. Pryor and R. J. Barthelmie, "Climate change impacts on wind energy: a review," Renewable and Sustainable Energy Reviews, vol. 14, no. 1, pp. 430-437, (2010)

2. World Wind Energy Association, World Wind Energy Report 2012, http://www.wwindea.org/home/images/ Stories /pdfs / world wind energy report, 2012.pdf, (accessed) August 10, (2013)

3. Bedon G, Schmidt Paulsen U, Aagaard Madsen H, Belloni F, Raciti Castelli M, Benini E. Computational assessment of the DeepWind aerodynamic performance with different blade and airfoil configurations. Appl Energy; 185(2):11008. (2017)

4. Qa Li, Kamada Y, Maeda T, Murata J, Okumura Y. Fundamental study on aerodynamic force of floating offshore wind turbine with cyclic pitch mechanism. Energy; 99:20-31. (2016)

5. Mertens, S., Wind energy in the built environment: Concentrator effects of buildings, TU Delft, pp.314, Multi-Science. (2006)

6. Mewburn-Crook, A., The design and development of an augmented vertical wind turbine, School of Mechanical, Aeronautical and Production Engineering, pp.1-59. (1990)

7. N.H. Mahmoud, A.A. El-Haroun, E. Wahba, M.H. Nasef., An experimental study on improvement of Savonius rotor performance, Alexandria Engineering Journal, 51, pp19-25. (2012)

8. Spera, D.A., Wind Turbine Technology, Second edition, ASME Press, Chapter 5, (2009). 
9. Firdaus, R., Kiwata, T., KONO, T., NAGAO, K. Numerical and Experimental Studies of a Small Vertical-Axis Wind Turbine with Variable-Pitch Straight Blades, Journal of Fluid Science and Technology, Vol. 10, No.1, pp.13 (2015).

10. Hwang, I.S. et. Al. "Efficiency Improvement of a New Vertical Axis Wind Turbine by individual Active Control of blade motion." Proceeding of SPIE. 6173-11 (2006)

11. Kiwata, T., Yamada, T., Kita, T., Takata, S., Komatsu, N., Kimura, S., Performance of a Vertical Axis Wind Turbine with Variable-pitch Straight Blades Utilizing a Linkage Mechanism, Journal of Environment and Engineering, Vol. 5, No.1, pp. 213-224 (2010)

12. Bayeul-Lainé A.C., Bois G., Unsteady simulation of flow in micro vertical axis wind turbine, Proceedings of 21st International Symposium on Transport Phenomena, Kaohsiung City Taiwan, 0205 November (2010)

13. Shimizu,Y., Maeda,T., Kamada,Y.Minamikawa, T.,Watanabe, T. "Performance Improvement Of The Orthopter Wind Turbine By The Diffuser". Japan Society Of Mechanical Engineers 1999 Annual Conference Proceedings, Pp.211-212. (1999) 